\title{
Self-perceptions of romantic appeal in adolescents with a cleft lip and/or palate
}

\begin{abstract}
During adolescence, romantic relationships are a key developmental milestone. Coupled with the increasing salience of appearance and social acceptance, adolescents with an appearancealtering condition may feel particularly vulnerable when it comes to romantic relationships. This study aimed to explore the prevalence of romantic experiences among adolescents with a cleft lip and/or palate $(\mathrm{CL} / \mathrm{P})$, and to investigate how these experiences could be related to depressive symptoms and global self-worth. The study included 661 adolescents with CL/P, who were compared to a large national sample. The prevalence of romantic relationships was lower among adolescents with CL/P compared to the reference group, although the overall impact on depressive symptoms and global self-worth appeared to be low. This study is one of few to explore the impact of a congenital visible condition on experiences of romantic relationships and provides preliminary insight into a significant, yet complex topic.
\end{abstract}

Key words: Romantic relationships, cleft lip and palate, self-perceptions, depressive symptoms, satisfaction with appearance, intimacy 


\section{Introduction}

During adolescence, the experience of romantic relationships is a key developmental milestone in the progression toward social maturity (Furman, 2002). Far from trivial, these relationships are a major topic of conversation among adolescents (Thompson, 1994), play a central role in the development of identity and close friendships (Furman, 2002; Furman \& Shaffer, 2003), and have significant implications for health, adjustment, and overall life satisfaction (Bouchey, 2007; Donaghue, 2009). Although it has long been recognised that adolescents' peer relations and friendships significantly contribute to psychological health, considerably less is known about the influence of romantic experiences (La Greca \& Harrison, 2005).

Romantic popularity has been shown to be associated with physical attractiveness (Feingold, 1990; Langlois et al., 2000), and with subjective appearance evaluations (Bale \& Archer, 2013). Appearance becomes increasingly salient during adolescence (Smolak, 2004). Coupled with the physical changes which take place at this key developmental stage and the pressure to conform to societal standards of beauty, adolescents can become preoccupied with their appearance and the appearance of others around them (Smolak, 2004). Such concerns may be exacerbated by an increased interest in forming romantic relationships during this developmental period (Markey \& Markey, 2006).

One group of adolescents who may be at risk of appearance dissatisfaction and exposed to appearance-related comments from peers, are those affected by an appearancealtering condition. The prevalence of young people with a 'significant' visible facial difference has been calculated to be between one in fifty and one in a hundred (Julian \& Partridge, 2008). This includes the most common craniofacial condition found in humans, cleft lip and/or palate (CL/P). Although the primary surgery to repair the cleft typically 
occurs during the child's first year of life, those affected by CL/P must engage in a multidisciplinary treatment pathway throughout childhood and into adulthood. Consequently, young people born with a cleft can feel they differ from their peers, particularly in relation to appearance (Rumsey \& Stock, 2013). These appearance concerns have the potential to impact significantly upon social experiences and emotional wellbeing (Rumsey, Clarke, White, WynWilliams, \& Garlick, 2004). Adolescents with CL/P may therefore feel particularly vulnerable when it comes to romantic relationships.

Up until the past two decades, research on adolescents' romantic experiences among the general population has been scarce (Furman, 2002). Concurrently, only a minority of studies have directly discussed the potential impact of a visible difference on the prevalence and reported experience of adolescent romantic relationships (Griffiths, Williamson, \& Rumsey, 2012). Some studies mention the potential importance of romantic relationships for this population only briefly, rather than focussing on the area as a primary topic of research interest (Feragen, Stock, \& Kvalem, 2015; Fox, Rumsey, \& Morris, 2007; Havstam, Laakso, \& Ringsberg, 2011; Stock, Feragen, \& Rumsey, in press; Tevik \& Feragen, 2015; Williams, Gannon, \& Soon, 2011). Interestingly, while a number of these studies report clear concerns regarding the negative impact of a visible difference on the chances of experiencing romantic relationships (Fox et al., 2007; Havstam et al., 2011; Williams et al., 2011), the overall impact on adjustment appears to be low in retrospect (Stock, Feragen, \& Rumsey, 2015). Further, one quantitative study reported self-perceptions of romantic appeal in adolescents with CL/P that were comparable to a same-aged reference group (Feragen et al., 2015). Inconclusive findings may partly be explained by the complex, multifaceted and fluctuating nature of selfperceptions, while also reflecting differences in age ranges, measures and constructs. Given the potential influence of romantic experiences upon psychosocial adjustment during adolescence, a key research priority should be to investigate factors that are associated with 
positive romantic self-perceptions, particularly among those with a visible difference who may be especially vulnerable.

Within the general population, a number of factors have been suggested to affect the relationship between romantic experiences and psychosocial adjustment. These include adolescents' reports of having had (or not had) a romantic relationship (Madsen \& Collins, 2011; Yu, Branje, Keijsers, \& Meeus, 2014), self-perceptions of romantic appeal (Bouchey, 2007), self-perceptions of social experiences and close friendships (Bouchey, 2007; Cash, Thériault, \& Annis, 2004; Furman \& Collins, 2011; Furman, Low, \& Ho, 2009), perceptions of relational and global self-worth (Harter, Waters, \& Whitesell, 1998), and self-perceived attractiveness and body image (Ambwani \& Strauss, 2007; Bale \& Archer, 2013). In parallel, depressive symptoms are known to increase during adolescence, particularly in females (Twenge \& Nolen-Hoeksema, 2002; Wichstrom, 1999), and have also been shown to be associated with experiences of dating during adolescence (Natsuaki, Biehl, \& Ge, 2009). It is therefore important to investigate correlates of depressive symptoms as a way of understanding these associations and of optimising psychological health (Chow, Ruhl, \& Buhrmester, 2015; Natsuaki et al., 2009). Given the centrality of appearance perceptions to social 'belonging' and psychological wellbeing in adolescence (Smolak, 2012), as well as the social status of having a romantic partner at this age (Brown, 1999), the impact of having a visible difference on young people's perceptions of romantic appeal, depressive symptoms and global self-worth should be explored further.

Gender differences have been demonstrated in young people with CL/P (Berger \& Dalton, 2009; Feragen et al., 2015), and within the general population (Franko \& StriegelMoore, 2002; Nolen-Hoeksema \& Girgus, 1994), with higher levels of appearance dissatisfaction and emotional distress found in young females compared to males. Thus, 
gender is an important variable when exploring concepts such as self-perceptions and depressive symptoms in adolescent samples. Another possible contributory factor in the relationship between $\mathrm{CL} / \mathrm{P}$ and romantic relationships could be how 'visible' the condition is to others. Although many studies have identified subjective perceptions of visibility to be more predictive of psychosocial adjustment than the objective 'severity' of the condition, many $\mathrm{CL} / \mathrm{P}$ studies still make reference to the importance of separating samples according to cleft type. For the purpose of the current study, analyses were therefore performed according to 'visible' (cleft lip, cleft lip alveolus) and 'nonvisible' (cleft palate, submucous cleft palate) cleft types. Finally, additional conditions, such as a genetic syndrome, developmental delay, or learning difficulty, are prevalent in young people with CL/P (Sivertsen et al., 2008) and are known to potentially affect psychological function (Feragen, Stock, \& Rumsey, 2014). Their presence, particularly in cleft samples, should thus be accounted for and controlled when possible (Feragen et al., 2014).

\section{The Present Study}

The paucity of research on the romantic experiences of those with a visible difference stands in sharp contrast to the importance of this factor in many people's lives. Romantic relationships play a central role in adolescent development, health, and overall satisfaction with life (Bouchey, 2007; Furman \& Shaffer, 2003), and has been shown to impact on appearance evaluations (Bale \& Archer, 2013). Young people with a visible difference may therefore be particularly vulnerable when it comes to satisfaction with appearance and romantic appeal, and could possibly struggle to initiate romantic relationships. Further, the negative impact of a visible difference on romantic experiences could be expected to be stronger in females, due to higher levels of appearance dissatisfaction and emotional distress in the general population as well as in those with a visible difference (Feragen et al., 2015; 
Franko \& Striegel-Moore, 2002). Nevertheless, few studies have specifically investigated the impact of a visible difference on adolescents' romantic experiences (Griffiths et al., 2012), and knowledge regarding the nature and extent of the potential impact of a visible condition on romantic relationships is therefore strongly needed.

The aim of the present study was to conduct preliminary investigation into possible associations between experiences of romantic relationships, self-perceptions of romantic appeal, global self-worth, and emotional adjustment in young people with CL/P at age 16, with the objective of informing future research in this area. More specifically, the aims were to: (a) investigate the prevalence of previous and current romantic relationships reported by adolescents with CL/P compared to same-aged adolescents without CL/P (b) investigate the impact of a number of relevant factors (gender, cleft visibility, additional conditions, satisfaction with appearance, self-perceptions of social acceptance and close friendships, and current and previous romantic relationships) which may contribute to the development of potential concerns, (c) and explore the impact of having had or not having had experience of being in a romantic relationship on levels of depressive symptoms and global self-worth.

\section{METHOD}

\section{Setting}

(Country) provides a centralised setting for CL/P treatment. The present study was based on case records of 16-year-old adolescents born with CL/P, collected from routine psychological clinical assessments within the (City)-team. This team that is responsible for two thirds of the entire cleft population, treating approximately 70 to 80 new babies born with CL/P per year. The team's clinical psychologist met with each participant before he or she completed a questionnaire. 
The present study conformed to the guidelines set by the local ethics committee (Regional Committee for Medical Research Ethics, Region (City)-East).

\section{Participants}

All adolescents $(\mathrm{N}=990)$ from 11 consecutive birth cohorts who attended the routine 16-year-old follow-up from January 2004 to June 2015 were eligible for inclusion in the study. Due to severe developmental problems, some adolescents $(n=61)$ were not able to attend the routine assessments, and most of their outcome measures are therefore missing. The remaining 929 young people were informed about the study and asked to participate. Forty nine young people declined participation (5.3\%), while 219 did not respond to the request for participation $(23.6 \%)$ and were therefore not included in the study. The participating sample hence included a total of 661 young people $(71.2 \%)$.

Among the cleft sample, 263 adolescents were female (39.8\%) and 398 adolescents were male (60.2\%). Adolescents' cleft type included cleft lip and palate (CLP, $n=260)$, cleft lip or cleft lip alveolus (CLA, $n=184)$, and cleft palate or submucous cleft palate (CP/SMCP, $n=217$ ). For the purpose of the statistical analyses, the adolescents were categorised into two groups: adolescents with visible clefts (CLP and CLA, $n=444)$ and adolescents with nonvisible clefts (CP/SMCP, $n=217)$. Among the girls, $46.3 \%$ had a nonvisible cleft and $53.6 \%$ had a visible cleft. Among the boys, $23.9 \%$ had a nonvisible cleft and $76.1 \%$ had a visible cleft. These figures are in line with expected prevalence rates for this population (Sivertsen et al., 2008).

Where available, the results from the adolescent cleft sample were compared to a large group of adolescents not affected by CL/P. This reference group consisted of 16-year olds (n $=1832 ; 888$ females, 944 males) who engaged in a national representative survey "Young in (Country) 2002', with a participation rate of $92.3 \%$. 
Information about additional diagnoses or conditions expected to affect cognitive and/or psychological functioning was gathered from the patient's case records, and/or was provided by the patient's parents. Information about potential additional conditions was missing for 63 participants. Among the remaining 598 participants, $21.7 \%(n=130)$ had one or more additional conditions, including developmental delay/difficulties $(n=31)$, dyslexia or specific language impairment $(n=27)$, autism spectrum disorder $(n=8)$ and Attention Deficit/Hyperactivity Disorder (AD/HD, $n=44)$. Furthermore, some adolescents had a diagnosed syndrome $(n=24)$, such as 22q11.2, Treacher Collins, or Goldenhar, with or without associated psychological and/or cognitive difficulties.

\section{Measures Completed by the CL/P Group}

Questionnaire for 16-year old patients. The Questionnaire for 16-year old patients (originally based on the Questionnaire for 15-year-old patients developed by the Psychology Clinical Excellence Network of the Craniofacial Society of Great Britain and Ireland), was used to collect information regarding current and previous romantic relationships. Questions included: "Do you have a boyfriend/girlfriend at the moment?" and "If not: Have you had a boyfriend/girlfriend in the past?"

Cleft Hearing, Appearance and Speech Questionnaire. The Cleft Hearing, Appearance and Speech Questionnaire (CHASQ, previously called SWA) was developed by the Psychology Clinical Excellence Network of the Craniofacial Society of Great Britain and Ireland. The CHASQ originally consists of 20 items and collects information regarding the patient's satisfaction with cleft-related and non-cleft-related features of the face, as well as satisfaction with speech, hearing, overall appearance and the perceived visibility of the cleft. However, only four items were used in the present study, measuring subjective satisfaction with general appearance, appearance of the face, subjective evaluations of cleft visibility, and 
the impact of $\mathrm{CL} / \mathrm{P}$ on social relationships. Each rating is made on an interval scale of 0 to 10 where a score of 10 indicates high levels of satisfaction. The mean total score of the 4 item version of the scale was calculated. The four-item version of the CHASQ has been reported to possess good validity and acceptable internal consistency $(\alpha=.75)$ in a same-aged, large and representative sample of adolescents with CL/P (Feragen et al., 2015).

Self-Perception Profile for Adolescents. The Self-Perception Profile for Adolescents, SPPA (Harter, 1988) is a 35 item scale designed to assess adolescents' selfperceptions in relation to a number of psychological domains. The (Country) version was used, which has been shown to achieve better reliability, better convergent validity, and a replication of the same factorial pattern than the original version (Wichstrom, 1995). The subscales contain five statements, each presented as a self-description. Responses were given on a scale from “'Describes me very poorly" (1) to “Describes me very well'” (4). A mean score ranging from 1 to 4 was computed. The following subscales were used in the present study: Social Acceptance, Physical Appearance, Romantic Appeal, Close Friendships and Global Self-Worth. All subscales were shown to have internal reliability scores that were acceptable/good (Social Acceptance: $\alpha=.69$; Close Friendship: $\alpha=78$; Romantic Appeal: $\alpha=$ .75 ) to excellent (Physical Appearance: $\alpha=.89$ ) in a similar same-aged, large and representative sample of adolescents with CL/P (Feragen et al., 2015).

Hopkins Symptom Checklist. The shortened version of the Hopkins Symptom Checklist, HSCL-25 (Kandel \& Davies, 1982) measures depressive symptoms through seven items (HSCL-7). Tambs and Moum (1993) have demonstrated that this strongly abbreviated version of the instrument correlates well $(r=.92)$ with the original HSCL-25. Each item, such as "Feeling unhappy, sad, or depressed"' and 'Feeling hopeless about the future," was rated on a frequency of occurrence over the preceding 14 days, ranging from never (1) to very 
much (4). Mean scores falling between the clinical cut-off score of 1.75 and 2.00 on the HSCL-7 are interpreted as moderate levels of depressive symptoms, while mean scores above 2.00 are indicative of severe levels of depressive symptoms (Rognerud, Strand, \& Dalgard, 2002). Internal consistency was high $(\alpha=.83)$ in a similar same-aged, large and representative sample of adolescents with CL/P (Feragen et al., 2015).

\section{Measures Completed by the Reference Group}

The reference group comprised of a large sample of adolescents who participated in a national survey. As a result, the reference group did not complete all of the measures used in this study, such as the CHASQ, which is a cleft-specific measure. The reference group did complete the HSCL-7 and the SPPA, unfortunately with the exception of the Romantic Appeal subscale.

\section{Statistical Analysis}

Statistical analyses were performed using SPSS 22 (IBM Corp, Armonk, NY). Most analyses were performed separately for males and females, given the well-known gender differences which are apparent at this age. For categorical variables, group differences were tested using Pearson's Chi-square. Bivariate associations were calculated using Pearson's $r$ correlation coefficient. A hierarchical multiple regression was used to test for the associations between the study variables and the outcome variables. Regression analyses were run separately for females and males. Given that the same variables were statistically significant in the regression analyses for both genders, the choice was made to perform only one regression analysis, controlling for gender in the first step, in order to keep statistical strength to a maximum. Effect sizes (semi partial $R^{2}$ ) were calculated and reported. Last, a one-way ANOVA with Tukey post hoc tests, reported as mean differences (MD) with corresponding standard errors (SE), was used to test for differences in means on the outcome variable 
between subgroups of participants. In cases of significant differences between means, Eta squared effect sizes $\left(\eta^{2}\right)$ were calculated.

\section{Results}

\section{Prevalence of Current and Previous Romantic Relationships}

The prevalence of adolescents who reported being in a current romantic relationship, having experience of a previous romantic relationship, or never having been in a romantic relationship are presented in Table 1 . As can be seen from the table, $18.9 \%(n=24)$ of the females with a visible cleft and $18.1 \%(n=21)$ of those with a nonvisible cleft reported being in a romantic relationship at the time of assessment, compared to $33.1 \%(n=294)$ of females from the reference group. Concordantly, a higher frequency of females with a visible cleft had never been in a romantic relationship $(50.4 \% ; n=64)$, compared to $37.9 \%(n=44)$ of females with a nonvisible cleft, and $28.5 \%(n=253)$ of females from the reference group. The difference within the female CL/P sample (nonvisible vs visible) was not statistically significant $\left(\chi^{2}=5.02, p>.05\right)$, while the difference between the female CL/P group (visible and nonvisible combined) and the reference group was significant $\left(\chi^{2}=28.60, p<.001\right)$.

In the group of males, $10.0 \%(n=27)$ of those with a visible cleft reported being in a romantic relationship at the time of assessment, compared to $11.9 \%(n=10)$ of those with a nonvisible cleft, and $19.0 \%(n=178)$ of the males in the reference group. Similarly, a higher frequency of young males with a visible cleft $(47.2 \%, n=128)$ and $47.6 \%(n=40)$ of males with a nonvisible cleft had never been in a romantic relationship, compared to same-aged males from the reference group $(29.1 \%, n=273)$. The difference within the CL/P sample (nonvisible and visible) was nonsignificant $\left(\chi^{2}=0.32, p>.05\right.$ ), while the difference between the $\mathrm{CL} / \mathrm{P}$ group (nonvisible and visible) and the reference group was significant $\left(\chi^{2}=41.28, p\right.$ $<.001)$. 
The prevalence of current and past romantic relationships in females and males was calculated a second time, in order to compare the group with a cleft only with those with a cleft and an associated condition. Among females with a cleft only, 24.4\% $(n=47)$ reported being in a current romantic relationship, compared to $13.3 \%(n=8)$ of the females with an additional condition. Further, $37.8 \%(n=73)$ of the females with a cleft only reported a previous romantic relationship, compared to $28.3 \%(n=17)$ of those with an additional condition. The largest difference was found when comparing those who reported that they had never experienced a romantic relationship: $37.8 \%(n=73)$ of the females with a cleft only, and $58.3 \%(n=35)$ of those with a cleft and an additional condition. The differences between the groups were statistically significant $\left(\chi^{2}=8.23, p<.05\right)$.

Of the males with a cleft only, a total of $9.7 \%(n=27)$ were in a current romantic relationship, $44.4 \%(n=124)$ had previous experiences of romantic relationships, and $45.9 \%$ $(n=128)$ had never been in a romantic relationship. In the group of males with a cleft and an additional condition, $13.2 \%(n=10)$ reported being in a romantic relationship at the time of assessment, $34.3 \%(n=23)$ had a previous experience, and 52.6\% $(n=40)$ had never experienced a romantic relationship. The difference in prevalence of romantic relationships were not statistically significant between males with a cleft only and males with a cleft and an additional condition $\left(\chi^{2}=2.75, p>.05\right)$.

\section{Bivariate Associations}

Bivariate associations between the study variables were calculated separately for females and males and are presented in Table 2. Associations were found between all variables and ranged from $r=.14$ to .69 , the highest associations being found between the two measures of satisfaction with appearance (females: $r=.69$; males: $r=.58, p<.001$ ), and 
between self-perceptions of social acceptance and close friendships (females: $r=.53$; males: $r$ $=.55, p<.001)$.

\section{Variables Associated with Self-Perceptions of Romantic Appeal}

Using data from participants with CL/P (nonvisible or visible), a hierarchical (four steps) multiple regression analysis was conducted to explore whether the following variables were associated with self-perceptions of romantic appeal: gender, cleft visibility, additional conditions, satisfaction with (general and cleft-related) appearance, self-perceptions of social acceptance and close friendships, and current and previous romantic relationships. The 'background' factors of gender, cleft visibility, and additional conditions were entered in the first step of the regression analysis, followed by subjective assessments of appearance in the second step, and self-perceptions of social experiences in the third step. Finally, reports of current and previous experience of romantic relationship were entered as a dummy variable in the final step. The results are presented in Table 3.

Variables found to be nonsignificant included cleft visibility, additional conditions (significant only in Step 2), satisfaction with appearance (CHASQ), and self-perceptions of close friendships.

Among the background factors, only gender explained variance in self-perceptions of romantic appeal, with males reporting higher levels of romantic appeal $\left(R^{2}=.09\right)$ in the first step of the analysis. In Step 2, gender, the presence of an additional condition, and selfperceptions of general physical appearance $(\mathrm{PhA})$ positively explained $26 \%$ of the total variance, while satisfaction with appearance as measured by the CHASQ (cleft and non-cleftrelated appearance) did not impact on self-perceptions of romantic appeal $(\beta=-.03, p>.05)$. In Step 3, gender, in addition to self-perceptions of physical appearance and social acceptance explained $36 \%$ of the variance. When adding current and previous experiences of romantic 
relationships into the last step, $41 \%$ of the total variance was explained by the same variables as in Step 3, with a supplementary impact of previous romantic relationships $\left(\Delta R^{2}=.05\right)$; a factor that strengthened self-perceptions of romantic appeal.

\section{The Impact of Romantic Relationships on Depressive Symptoms}

Calculations of mean scores showed that young females with a cleft reported significantly fewer depressive symptoms than same-aged females from the reference group, $F(1,1121)=14.94, p<.001$. Mean scores can be found in Table 4 and were within the normal range for both cleft groups (visible and nonvisible), while in the borderline clinical range for the reference group. Similarly, males from the reference group reported more depressive symptoms than the CL/P group, with the lowest levels being found in young males with a visible cleft, $F(1,1292)=79.91, p<.001$. Mean scores were within the normal range for all subgroups of males.

Mean scores for depressive symptoms were calculated for the three subgroups within the reference group and the CL/P sample: young people who reported being in a current romantic relationship, those who had been in a previous romantic relationship, and those who had never been in a romantic relationship. The results are presented in Table 4 and show that none of the differences in depressive symptoms between the groups were statistically significant.

\section{The Impact of Romantic Relationships on Global Self-Worth}

Calculations of mean scores showed that young females with a cleft reported significantly more positive global self-worth than same-aged females from the reference group, $F(1,1126)=5.93, p<.05$. The same was the case for the males, $F(1,1300)=45.90, p$ $<.001$. 
Mean scores for global self-worth were calculated for the same three subgroups within the sample (current, previous or no experience of romantic relationships), within the CL/P subgroups and the reference group. The results are presented in Table 4 and show that there were no statistically significant differences in global self-worth between the groups, except within the reference group. Males from the reference group who reported to have been in a previous romantic relationship had more positive global self-perceptions than males from the reference group who reported to never have had a romantic partner, $F(1,931)=3.05 ; M D=$ $0.11, S E=.05, p<.05$. Effect size, however, was small $\left(\eta^{2}=0.007\right)$.

\section{Discussion}

This study is the first quantitative study to investigate associations between experiences of romantic relationships, self-perceptions of romantic appeal, global self-worth and emotional adjustment in adolescents with CL/P. The effects of gender, cleft visibility, additional conditions, self-perceptions of social acceptance and close friendships, satisfaction with general physical appearance, and satisfaction with cleft-affected appearance and visibility on self-perceptions of romantic appeal were also explored.

\section{The Impact of Romantic Relationships on Psychological Wellbeing}

Compared to the reference group, significantly fewer adolescents with CL/P reported being in a romantic relationship at the time of the age 16 assessments. This figure is also lower than that previously reported within the general population (Carver, Joyner, \& Udry, 2003). Concurrently, significantly more adolescents with CL/P reported having never had a romantic relationship compared to same-age peers not affected by CL/P. These findings were true of both males and females with CL/P, and were also prominent among females with a cleft and an additional condition. 
These results seem to be in line with previous research in the field of CL/P, which has suggested that young adults may struggle to initiate romantic relationships (Ramstad, Ottem, $\&$ Shaw, 1995). The fear of initiating a relationship and of rejection from potential partners has also been reported as a concern among adults with CL/P (Stock et al., in press) and among those with other visible conditions, such as psoriasis and acne (Fox et al., 2007; Murray \& Rhodes, 2005; Wahl, Gjengedal, \& Hanestad, 2002). In Griffiths et al. (2011), 73\% ( $n=29)$ had experience of having a relationship and $23 \%(n=9)$ were currently in a relationship at the time of the study. Further, $43 \%$ reported concerns about current or future romantic relationships (Griffiths et al., 2011). Qualitative CL/P studies have also pointed to adolescents' first relationship as an important confirmation of their attractiveness, and a key part of the process toward becoming confident in romantic relationships (Havstam et al., 2011; Stock et al., in press). Of particular concern, is that among the general population, appearance-related rejection sensitivity during adolescence has been found to decrease the likelihood of future romantic relationships as a young adult (Hafen, Spiker, Chango, Marsten \& Allen, 2014).

When taking previous findings into account, and given the known importance of romantic relationships and social 'belonging' during the adolescent years, it could be assumed that a lack of romantic experiences could impact substantially upon young people's emotional wellbeing and evaluations of self-worth. Yet in the current study, depressive symptoms and global self-worth were not found to vary significantly between those who had, or those who had never experienced a romantic relationship. Previous and current findings therefore indicate that while having had a previous relationship may strengthen self-perceptions of romantic appeal (Furman \& Winkles, 2010; Madsen \& Collins, 2011), not having had a romantic relationship may not have a large enough impact on its own to cause distress at the age of 16 . 
A further interesting finding of the present study is that reports of emotional wellbeing and global self-worth were found to be greater among adolescents born with CL/P when compared to the reference group. Recent research has begun to explore the development of positive personal attributes and resilience among those with a visible difference as one explanation for findings such as these (Egan, Harcourt, \& Rumsey, 2011; Stock et al., in press). In the context of romantic relationships, a recent qualitative study suggested that young people with CL/P may have less tolerance for frivolous or short-term relationships as a result of their visible difference, and may make a conscious choice to wait for a suitable partner who is accepting of their difference (Stock et al., in press). It could be that at least some young people with a visible difference attribute their lack of romantic experience to a personal choice, rather than a consequence of their condition (Stock et al., in press), and that this attribution could serve as a protective factor for emotional distress. Another possible protective factor offered by recent research is the ability to value the contribution of nonappearance-related attributes when attracting a partner (Appearance Research Collaboration, 2009; Griffiths et al., 2012; Stock et al., in press). Other potential explanations derived from more general literature include the timing of data collection, and the negative impact of romantic relationships. In regard to the former, the known increase in relationship duration and meaning over time suggests that the absence of romantic experiences may be more detrimental to psychological health in early adulthood (Seiffge-Krenke, 2003), and therefore less detectable at the age of 16 . In relation to the latter, prior research has found that the act of engaging in a romantic relationship can itself impact upon emotional wellbeing and selfworth in a less favourable way, particularly among females (La Greca \& Harrison, 2005; Seiffge-Krenke, 2003).

\section{Romantic Appeal and Satisfaction with Appearance}


In the current study, self-perceptions of general physical appearance (as measured by the SPPA) accounted for approximately $15 \%$ of the variance in self-perceived romantic appeal. This finding is in line with wider literature, which suggests that self-perceptions of overall physical appearance are related to self-reports of romantic appeal and romantic satisfaction (Furman \& Winkles, 2010; Tantleff-Dunn \& Gokee, 2002). Interestingly, selfperceived romantic appeal was not significantly impacted by self-reported satisfaction with facial features directly affected by CL/P (as measured by the CHASQ). Similarly, neither self-perceived visibility of the cleft (as measured by the CHASQ) nor 'objective' visibility (as distinguished by cleft type) impacted upon self-reports of romantic appeal.

These results suggest that while satisfaction with general appearance can play an important role in perceptions of romantic appeal, the impact of having a condition such as $\mathrm{CL} / \mathrm{P}$ appears to be low, at least at age 16, and does not exceed the impact of normative appearance concerns. Prior qualitative studies have indicated that young people affected by a visible difference may rationalise any romantic anxieties which they experience as being typical of all adolescents, rather than attributing these concerns directly to their condition (Egan et al., 2011; Griffiths et al., 2012); another cognitive processing style which may serve as a protective factor for emotional distress. These findings suggest the need for researchers and clinicians to distinguish between aspects of appearance which may be directly affected by the objective presence of a facial difference, and aspects of general satisfaction with appearance which could be more resilient to the objectivity of a difference, due to its connectedness with individual and attributional factors. Subjective measures of appearance satisfaction should be incorporated alongside more 'objective' measures of appearance (such as 'cleft visibility' in the current study), in order to disentangle the relationship between normative appearance concerns and those attributed to or exacerbated by a visible difference. 


\section{The Role of Social Acceptance and Close Friendships}

In the present study, self-perceptions of social acceptance were found to impact upon self-perceived romantic appeal, accounting for $10 \%$ of the variance. This is in line with previous research in the field of visible difference, which suggests that having close friends can reinforce feelings of social acceptance, and buffer appearance-related concerns (Feragen, Kvalem, Rumsey, \& Borge, 2010; La Greca, Bearman, \& Moore, 2002). This effect may be particularly pertinent if these friends are of the opposite sex (Griffiths et al., 2012), as also demonstrated among young people with chronic conditions (La Greca, 1990; La Greca et al., 2002), and within the general population (Carver et al., 2003).

Surprisingly, and in contrast to previous literature in this area (Connolly, Furman, \& Konarski, 2000; Furman et al., 2009; Furman \& Shomaker, 2008; La Greca \& Mackey, 2007), perceptions of close friendships did not significantly influence reports of self-perceived romantic appeal. Nevertheless, self-perceptions of romantic appeal and close friendships were significantly associated. It is known that adolescents' first relationships often develop from being in a mixed friendship group (Connolly, Craig, Goldberg, \& Pepler, 2004). However, those with a perceived disability may be more readily accepted as friends, and less readily accepted as a potential romantic partner (Milligan \& Neufeldt, 2001; Pausch et al., 2015; Shuttleworth, 2000), suggesting that close friendships may enhance social acceptance, but not necessarily romantic appeal in young people with a visible difference. Past research has also proposed that judgements associated with concepts such as self-perceived romantic appeal and close friendships are related to different, but not entirely distinct facets of self-worth; a theory which requires further investigation (Furman and Winkles, 2010; Harter et al., 1998). 


\section{The Potential Impact of Additional Conditions}

Females with a cleft and an additional condition reported significantly fewer experiences of romantic experiences than females with a cleft only. This difference was not found in the group of males, indicating a gender-related effect of an additional condition during adolescence. However, when including this variable in the regression analysis, no effect of an additional condition was found on self-perceptions of romantic appeal. To the authors' knowledge, no research has explored this issue within the area of visible difference. Within the general population, however, studies have investigated the impact of conditions such as developmental problems, learning difficulties and problems with attention (Stein, Blum, \& Barbaresi, 2011), describing a vast variation in how different conditions may impact on romantic experiences. This literature concludes that individuals with moderate to severe developmental difficulties may be less likely to marry and have children, and may be lacking the social skills to meet new friends and sustain relationships (Goldberg, Higgins, Raskind, \& Herman, 2003; Hellendoorn \& Ruijssenaars, 2000). However, for those with more mild conditions, such as learning difficulties or problems with attention, findings are less homogeneous (Stein et al., 2011). The present cleft sample included a wide variation of associated conditions, ranging from mild to severe in their impact on general psychological adjustment. However, young people with severe developmental difficulties were less likely to attend the routine assessment and to complete the questionnaire, indicating that the majority of the participants included in the study had less-impacting conditions. Hence, results from the present study seem to be in line with findings investigating less severe conditions in the general population.

\section{Strengths and Limitations}


The present study had a number of strengths. First, data from 11 consecutive birth cohorts were collected from within a centralised treatment setting, providing a highly representative and large sample. Second, a number of well-known and valid questionnaires were used. Finally, data from a same-aged reference group, who had completed many of the same measures, were used as a comparison.

Nonetheless, a number of limitations should be acknowledged. Of primary importance is the lack of information relating to a number of additional variables of interest, which could be expected to impact on the initiation and experience of romantic relationships. Variables of general interest include the quantity, duration and perceived quality of current and previous relationships (Whitton \& Kuryluk, 2012; Zimmer-Gembeck, Siebenbruner, \& Collins, 2001), the psychological impact of previous break-ups (Donald, Dower, CorreaVelez, \& Jones, 2006; La Greca \& Harrison, 2005; Monroe, Rohde, Seeley, \& Lewinsohn, 1999; Vajda \& Steinbeck, 2000), pubertal timing (Compian, Gowen, \& Hayward, 2004; Natsuaki et al., 2009), interpersonal attachment patterns (Cash et al., 2004), other personality variables (Cash et al., 2004; Yu et al., 2014) and levels of rejection sensitivity (Hafen, Spilker, Chango, Marston, \& Allen, 2014). Condition-specific variables of interest could include the degree of speech and language impairment (Havstam et al., 2011), the current phase of treatment which the young person is engaged in, their subsequent adjustment to any cosmetic or functional surgical alterations (Stock et al., 2015; Tevik \& Feragen, 2015) and fears around engaging in intimate behaviours, such as kissing (Havstam et al., 2011). Studies in the wider field of visible difference have also highlighted the potential importance of several other factors on the experience of romantic relationships and intimacy. These include questions such as whether the visible difference is congenital or acquired and the location of the difference on the body (Appearance Research Collaboration, 2009). The functional implications and connotations of the mouth, which may lead to fears about engaging in 
intimate behaviours such as kissing in those affected by CL/P (Havstam et al., 2011) could also be a potentially interesting area of future research. Exploration of additional variables in the present study was not possible given the retrospective nature of the data presented, but would provide an interesting avenue for future research.

Another limitation of the present study was that unfortunately, almost $30 \%$ of the participants were not reached or declined participation, and were therefore excluded from the analyses. In addition, data were based only on self-report measures, where multiple informants could potentially have provided a more comprehensive picture. A final limitation was that data relating to two of the study variables were not available for the reference group; namely self-perceptions of romantic appeal and satisfaction with features of the face affected by $\mathrm{CL} / \mathrm{P}$, potentially impeding comparisons across the two samples in the regression analysis. Further, the data from the reference group were collected in 2002, while data for the study sample were collected across eleven years. Data for a new reference group was collected in 2010 with an identical sampling procedure, and comparisons between the two reference groups showed that the prevalence of high scores on depressive symptoms did not increase between 2002 and 2010 (von Soest \& Wichstrøm, 2014). Information about the frequency of romantic relationships in the 2010 cohort (reference group) has not been published, and the present study can therefore not eliminate the possibility that the comparison between the 2010 reference group and the study sample could have been somewhat different.

\section{Conclusions}

This study is one of the first to explore the impact of a visible condition on the experience of romantic relationships in a large sample of adolescents. Findings suggest that although the prevalence of current or previous romantic relationships was lower among those with $\mathrm{CL} / \mathrm{P}$ when compared to an age-matched reference group, the overall impact on self- 
reported depressive symptoms and global self-worth appeared to be low. Further, satisfaction with the appearance of cleft-affected facial features was not related to self-perceptions of romantic appeal, indicating that the additional influence of $\mathrm{CL} / \mathrm{P}$ on this key variable, at least at age 16, does not exceed normative appearance concerns. Nonetheless, self-reports of social acceptance, as well as satisfaction with general appearance did play a role in self-perceptions of romantic appeal, and should thus be taken into account when treating and understanding the challenges related to psychological wellbeing among adolescents, regardless of the presence of a visible difference. Finally, the current lack of research on the romantic experiences of those with a visible difference stands in sharp contrast to the importance of this factor in many people's lives. The present study has provided much-needed preliminary insight into this significant yet complex topic, and a starting point from which future work may be based.

Acknowledgements: This project was partly financed by funds from the Norwegian Foundation for Health and Rehabilitation, project number 2011/0198. 


\section{References}

Appearance Research Collaboration (2009). Identifying factors and processes contributing to successful adjustment to disfiguring conditions. Final report, Centre for Appearance Research, University of the West of England, Bristol, UK.

Ambwani, S., \& Strauss, J. (2007). Love thyself before loving others? A qualitative and quantitative analysis of gender differences in body image and romantic love. Sex Roles, 56, 13-21. doi: 10.1007/s11199-006-9143-7

Bale, C., \& Archer, J. (2013). Self-perceived attractiveness, romantic desirability and selfesteem: A mating sociometer perspective. Evolutionary Psychology, 11, 68-84. doi: $10.1177 / 147470491301100107$

Berger, Z. E., \& Dalton, L. J. (2009). Coping with a cleft: Psychosocial adjustment of adolescents with a cleft lip and palate and their parents. Cleft Palate - Craniofacial Journal, 46, 435-443. doi: 10.1597/08-093.1

Bouchey, H. A. (2007). Perceived romantic competence, importance of romantic domains, and psychosocial adjustment. Journal of Clinical Child and Adolescent Psychology, 36, 503-514. doi: 10.1080/15374410701653120

Brown, B. B. (1999). “You're going out with who?”: Peer group influences on adolescent romantic relationships. In W. Furman, B. B. Brown \& C. Feiring (Eds.), The development of romantic relationships in adolescence (pp. 291-329). Cambridge, UK: Cambridge University Press.

Carver, K., Joyner, K., \& Udry, J. R. (2003). National estimates of adolescent romantic relationships Adolescent romantic relations and sexual behavior: Theory, research, and practical implications (pp. 23-56). Mahwah, NJ, US: Lawrence Erlbaum Associates Publishers.

Cash, T. F., Thériault, J., \& Annis, N. M. (2004). Body image in an interpersonal context: Adult attachment, fear of intimacy and social anxiety. Journal of Social and Clinical Psychology, 23, 89-103. doi: 10.1521/jscp.23.1.89.26987

Chow, C. M., Ruhl, H., \& Buhrmester, D. (2015). Romantic relationships and psychological distress among adolescents: Moderating role of friendship closeness. International Journal of Social Psychiatry, 61, 711-720. doi: 10.1177/0020764015585329

Compian, L., Gowen, L. K., \& Hayward, C. (2004). Peripubertal girls' romantic and platonic involvement with boys: Associations with body image and depression symptoms. Journal of Research on Adolescence, 14, 23-47. doi: 10.1111/j.15327795.2004.01401002.x 
Connolly, J., Craig, W., Goldberg, A., \& Pepler, D. (2004). Mixed-gender groups, dating, and romantic relationships in early adolescence. Journal of Research on Adolescence, 14, 185-207. doi: 10.1111/j.1532-7795.2004.01402003.x

Connolly, J., Furman, W., \& Konarski, R. (2000). The role of peers in the emergence of heterosexual romantic relationships in adolescence. Child Development, 71, 13951408. doi: 10.1111/1467-8624.00235

Donaghue, N. (2009). Body satisfaction, sexual self-schemas and subjective well-being in women. Body Image, 6, 37-42. doi: 10.1016/j.bodyim.2008.08.002

Donald, M., Dower, J., Correa-Velez, I., \& Jones, M. (2006). Risk and protective factors for medically serious suicide attempts: A comparison of hospital-based with populationbased samples of young adults. Australian \& New Zealand Journal of Psychiatry, 40, 87-96. doi: 10.1111/j.1440-1614.2006.01747.x

Egan, K., Harcourt, D., \& Rumsey, N. (2011). A qualitative study of the experiences of people who identify themselves as having adjusted positively to a visible difference. Journal of Health Psychology, 16, 739-749. doi: 10.1177/1359105310390246

Feingold, A. (1990). Gender differences in effects of physical attractiveness on romantic attraction: A comparison across five research paradigms. Journal of Personality and Social Psychology, 59, 981-993. doi/10.1037/0022-3514.59.5.981

Feragen, K. B., Kvalem, I. L., Rumsey, N., \& Borge, A. I. (2010). Adolescents with and without a facial difference: The role of friendships and social acceptance in perceptions of appearance and emotional resilience. Body Image, 7, 271-279. doi: 10.1016/j.bodyim.2010.05.002

Feragen, K. B., Stock, N. M., \& Kvalem, I. L. (2015). Risk and protective factors at age 16: Psychological adjustment in children with a cleft lip and/or palate. Cleft Palate Craniofacial Journal, 52, 555-573. doi: 10.1597/14-063

Feragen, K. B., Stock, N. M., \& Rumsey, N. (2014). Toward a reconsideration of inclusion and exclusion criteria in cleft lip and palate: Implications for psychological research. Cleft Palate - Craniofacial Journal, 51, 569-578. doi: 10.1597/12-326

Fox , F. E., Rumsey, N., \& Morris, M. (2007). "Ur skin is the thing that everyone sees and you cant change it!": Exploring the appearance-related concerns of young people with psoriasis. Developmental Neurorehabilitation, 10, 133-141. doi: $10.1080 / 13638490701217594$

Franko, D. L., \& Striegel-Moore, R. H. (2002). The role of body dissatisfaction as a risk factor for depression in adolescent girls: Are the differences Black and White? Journal of Psychosomatic Research, 53, 975-983. doi:10.1016/S0022-3999(02)00490-7

Furman, W. (2002). The emerging field of adolescent romantic relationships. Current Directions in Psychological Science, 11, 177-180. doi: 10.1111/1467-8721.00195 
Furman, W., \& Collins, W. A. (2011). Adolescent romantic relationships and experiences. In W. M. Bukowski, K. H. Rubin \& B. P. Laursen (Eds.), Handbook of peer interactions, relationships, and groups (pp. 341-360). New York, USA: Guilford Publications.

Furman, W., Low, S., \& Ho, M. J. (2009). Romantic experience and psychosocial adjustment in middle adolescence. Journal of Clinical Child and Adolescent Psychology, 38, 7590. doi: 10.1080/15374410802575347

Furman, W., \& Shaffer, L. (2003). The role of romantic relationships in adolescent development Adolescent romantic relations and sexual behavior: Theory, research, and practical implications (pp. 3-22). Mahwah, NJ, US: Lawrence Erlbaum Associates Publishers.

Furman, W., \& Shomaker, L. B. (2008). Patterns of interaction in adolescent romantic relationships: Distinct features and links to other close relationships. Journal of Adolescence, 31, 771-788. doi: 10.1016/j.adolescence.2007.10.007

Furman, W., \& Winkles, J. K. (2010). Predicting romantic involvement, relationship cognitions, and relationship qualities from physical appearance, perceived norms, and relational styles regarding friends and parents. Journal of Adolescence, 33, 827-836. doi: 10.1016/j.adolescence.2010.07.004

Goldberg, R. J., Higgins, E. L., Raskind, M. H., \& Herman, K. L. (2003). Predictors of success in individuals with learning disabilities: A qualitative analysis of a 20-year longitudinal study. Learning Disabilities Research \& Practice, 18, 222-236. doi: $10.1111 / 1540-5826.00077$

Griffiths, C., Williamson, H., \& Rumsey, N. (2012). The romantic experiences of adolescents with a visible difference: Exploring concerns, protective factors and support needs. Journal of Health Psychology, 17, 1053-1064. doi: 10.1177/1359105311433909

Hafen, C. A., Spilker, A., Chango, J., Marston, E. S., \& Allen, J. P. (2014). To accept or reject? The impact of adolescent rejection sensitivity on early adult romantic relationships. Journal of Research on Adolescence, 24, 55-64. doi: 10.1111/jora.12081

Harter, S. (1988). Manual for the Self-perception Profile for Adolescents: University of Denver.

Harter, S., Waters, P., \& Whitesell, N. R. (1998). Relational self-worth: Differences in perceived worth as a person across interpersonal contexts among adolescents. Child Development, 69, 756-766. doi: 10.1111/j.1467-8624.1998.tb06241.x

Havstam, C., Laakso, K., \& Ringsberg, K. C. (2011). Making sense of the cleft. Young adults' accounts of growing up with a cleft and deviant speech. Journal of Health Psychology, 16, 22-30. doi: 10.1177/1359105310367529

Hellendoorn, J., \& Ruijssenaars, W. (2000). Personal experiences and adjustment of Dutch adults with dyslexia. Remedial and Special Education, 21, 227-239. doi: $10.1177 / 074193250002100405$ 
IBM Corp. (2013). IBM SPSS Statistics for Windows, Version 22.0. Armonk, NY: IBM Corporation.

Julian, D., \& Partridge, J. (2008). The incidence and prevalence of disfigurement. London, UK: Changing Faces.

Kandel, D. B., \& Davies, M. (1982). Epidemiology of depressive mood in adolescents: An empirical study. Archives of General Psychiatry, 39, 1205-1212.

DOI:10.1001/archpsyc.1982.04290100065011

La Greca, A. M. (1990). Social consequences of pediatric conditions: Fertile area for future investigation and intervention. Journal of Pediatric Psychology, 15, 285-307. doi: 10.1093/jpepsy/15.3.285

La Greca, A. M., Bearman, K. J., \& Moore, H. (2002). Peer relations of youth with pediatric conditions and health risks: promoting social support and healthy lifestyles. Journal of Developmental and Behavioral Pediatrics, 23, 271-280. doi: 0196-206X/00/23040271

La Greca, A. M., \& Harrison, H. M. (2005). Adolescent peer relations, friendships, and romantic relationships: Do they predict social anxiety and depression? Journal of Clinical Child and Adolescent Psychology, 34, 49-61. doi: 10.1207/s15374424jccp3401_5

La Greca, A. M., \& Mackey, E. R. (2007). Adolescents' anxiety in dating situations: The potential role of friends and romantic partners. Journal of Clinical Child and Adolescent Psychology, 36, 522-533. doi: 10.1080/15374410701662097

Langlois, J. H., Kalakanis, L., Rubenstein, A. J., Larson, A., Hallam, M., \& Smoot, M. (2000). Maxims or myths of beauty? A meta-analytic and theoretical review. Psychological Bulletin, 126, 390-423. doi: 10.1037/0033-2909.126.3.390

Madsen, S. D., \& Collins, W. A. (2011). The salience of adolescent romantic experiences for romantic relationship qualities in young adulthood. Journal of Research on Adolescence, 21, 789-801. doi: 10.1111/j.1532-7795.2011.00737.x

Markey, C., \& Markey, P. (2006). Romantic relationships and body satisfaction among young women. Journal of Youth and Adolescence, 35, 256-264. doi: 10.1007/s 10964-0059013-6

Milligan, M., \& Neufeldt, A. (2001). The myth of asexuality: A survey of social and empirical evidence. Sexuality and Disability, 19, 91-109. doi: 10.1023/A:1010621705591

Monroe, S. M., Rohde, P., Seeley, J. R., \& Lewinsohn, P. M. (1999). Life events and depression in adolescence: Relationship loss as a prospective risk factor for first onset of major depressive disorder. Journal of Abnormal Psychology, 108, 606-614. doi/10.1037/0021-843X.108.4.606 
Murray, C. D., \& Rhodes, K. (2005). 'Nobody likes damaged goods': The experience of adult visible acne. British Journal of Health Psychology, 10, 183-202. doi: $10.1348 / 135910705 \times 26128$

Natsuaki, M. N., Biehl, M. C., \& Ge, X. (2009). Trajectories of depressed mood from early adolescence to young adulthood: The effects of pubertal timing and adolescent dating. Journal of Research on Adolescence, 19, 47-74. doi: 10.1111/j.15327795.2009.00581.x

Nolen-Hoeksema, S., \& Girgus, J. S. (1994). The emergence of gender differences in depression during adolescence. Psychological Bulletin, 115, 424-443.

Pausch, N. C., Winter, K., Halama, D., Wirtz, C., Yildirim, V., \& Nattapong, S. (2015). Psychosocial acceptance of cleft patients: has something changed? Oral Maxillofacial Surgery. Epub ahead of print. doi: 10.1007/s10006-015-0518-1

Ramstad, T., Ottem, E., \& Shaw, W. C. (1995). Psychosocial adjustment in Norwegian adults who had undergone standardised treatment of complete cleft lip and palate. I. Education, employment and marriage. Scandinavian Journal of Plastic and Reconstructive Surgery and Hand Surgery, 29, 251-257. http://dx.doi.org/10.3109/02844319509050135

Rognerud, M., Strand, B. H., \& Dalgard, O. S. (2002). Psykisk helse i Helse- og levekårsundersøkelsen i 1998. 1. Sosioøkonomiske forskjeller i psykisk helse og livsstil (Mental health in Norway 1998. Socioeconomic differences in mental health and lifestyle). Norsk Epidemiologi, 12, 239-248.

Rumsey, N., Clarke, A., White, P., Wyn-Williams, M., \& Garlick, W. (2004). Altered body image: Appearance-related concerns of people with visible disfigurement. Journal of Advanced Nursing, 48, 443-453. doi: 10.1111/j.1365-2648.2004.03227.x

Rumsey, N., \& Stock, N. M. (2013). Living with a cleft: Psychological challenges, support and intervention. In S. Berkowitz (Ed.), Cleft lip and palate. Diagnosis and management (pp. 907-915). Chicago, IL, USA: Springer Berlin Heidelberg.

Seiffge-Krenke, I. (2003). Testing theories of romantic development from adolescence to young adulthood: Evidence of a developmental sequence. International Journal of Behavioral Development, 27, 519-531. doi: 10.1080/01650250344000145

Shuttleworth, R. P. (2000). The search for sexual intimacy for men with cerebral palsy. Sexuality and Disability, 18, 263-282. doi: 10.1023/a:1005646327321

Sivertsen, A., Wilcox, A., Johnson, G. E., Abyholm, F., Vindenes, H. A., \& Lie, R. T. (2008). Prevalence of major anatomic variations in oral clefts. Plastic and Reconstructive Surgery, 121, 587-595. doi: 10.1097/01.prs.0000297839.78179.f5

Smolak, L. (2004). Body image in children and adolescents: Where do we go from here? Body Image, 1, 15-28. doi: 10.1016/s1740-1445(03)00008-1 
Smolak, L. (2012). Appearance in childhood and adolescence. In N. Rumsey \& D. Harcourt (Eds.), The Oxford Handbook of the Psychology of Appearance (pp. 123-141). Oxford, UK: Oxford University Press.

Stein, D. S., Blum, N. J., \& Barbaresi, W. J. (2011). Developmental and behavioral disorders through the life span. Pediatrics, 128, 364-373. doi: 10.1542/peds.2011-0266

Stock, N. M., Feragen, K. B., \& Rumsey, N. (in press). Adults' narratives of growing up with a cleft lip and/or palate: Factors associated with psychological adjustment. Cleft Palate - Craniofacial Journal. doi: 10.1597/14-269

Stock, N. M., Feragen, K. B., \& Rumsey, N. (2015). "It doesn't all just stop at 18": Psychological adjustment and support needs of adults born with cleft lip and/or palate. Cleft Palate - Craniofacial Journal, 52, 543-554. doi: 10.1597/14-178

Tambs, K., \& Moum, T. (1993). How well can a few questionnaire items indicate anxiety and depression? Acta Psychiatrica Scandinavica, 87(5), 364-367. doi: 10.1111/j.16000447.1993.tb03388.x

Tantleff-Dunn, S., \& Gokee, J. L. (2002). Interpersonal influences on body image development. In T. F. Cash \& T. Pruzinsky (Eds.), Body image: A handbook of theory, research, and clinical practice (pp. 108-116). New York, USA: Guilford Press.

Tevik, F., \& Feragen, K. B. (2015). 'I want the way I look to matter less': A case study describing psychological aspects of changing appearance. Clinical Child Psychology and Psychiatry, 20, 626-639. doi: 10.1177/1359104514542303

Thompson, S. (1994). Changing lives, changing genres; Teenage girls' narratives about sex and romance, 1978-1886. In A. S. Rossi (Ed.), Sexuality across the life course (pp. 209-232). Chicago, USA: University of Chicago Press.

Twenge, J. M., \& Nolen-Hoeksema, S. (2002). Age, gender, race, socioeconomic status, and birth cohort differences on the children's depression inventory: A meta-analysis. Journal of Abnormal Psychology, 111, 578-588. doi/10.1037/0021-843X.111.4.578

Vajda, J., \& Steinbeck, K. (2000). Factors associated with repeat suicide attempts among adolescents. Australian \& New Zealand Journal of Psychiatry, 34, 437-445. doi: 10.1080/j.1440-1614.2000.00712.x

von Soest, T., \& Wichstrøm, L. (2014). Secular trends in depressive symptoms among Norwegian adolescents from 1992 to 2010. Journal of Abnormal Child Psychology, 42, 403-415. doi: 10.1007/s10802-013-9785-1

Wahl, A. K., Gjengedal, E., \& Hanestad, B. R. (2002). The bodily suffering of living with severe psoriasis: In-depth interviews with 22 hospitalized patients with psoriasis. Qualitative Health Research, 12, 250-261. doi: 10.1177/104973202129119874 
Whitton, S. W., \& Kuryluk, A. D. (2012). Relationship satisfaction and depressive symptoms in emerging adults: Cross-sectional associations and moderating effects of relationship characteristics. Journal of Family Psychology, 26, 226-235. doi: 10.1037/a0027267

Wichstrom, L. (1995). Harter's Self-Perception Profile for Adolescents: reliability, validity, and evaluation of the question format. Journal of Personality Assessment, 65, 100116. doi: 10.1207/s15327752jpa6501_8

Wichstrom, L. (1999). The emergence of gender difference in depressed mood during adolescence: The role of intensified gender socialization. Developmental Psychology, 35, 232-245. doi.org/10.1037/0012-1649.35.1.232

Williams, E. F., Gannon, K., \& Soon, K. (2011). The experiences of young people with Epidermolysis Bullosa Simplex: A qualitative study. Journal of Health Psychology, 16, 701-710. doi: 10.1177/1359105310387954

Yu, R., Branje, S., Keijsers, L., \& Meeus, W. (2014). Brief report: How adolescent personality moderates the effect of love history on the young adulthood romantic relationship quality? Journal of Adolescence, 37, 749-752. doi:

10.1016/j.adolescence.2014.02.006

Zimmer-Gembeck, M. J., Siebenbruner, J., \& Collins, W. A. (2001). Diverse aspects of dating: Associations with psychosocial functioning from early to middle adolescence. Journal of Adolescence, 24, 313-336. doi: http://dx.doi.org/10.1006/jado.2001.0410 
Table 1. Prevalence of romantic relationships comparing young people with a visible and nonvisible cleft with an age-matched reference group across gender.

\begin{tabular}{lccccc}
\hline & Visible & Nonvisible & Ref. group & $\begin{array}{c}\text { Visible vs } \\
\text { Nonvisible }\end{array}$ & $\begin{array}{c}\text { Cleft vs } \\
\text { Ref.group }\end{array}$ \\
\cline { 2 - 6 } & $\%(n)$ & $\%(n)$ & $\%(n)$ & $\chi^{2}$ & $\chi^{2}$ \\
\hline Females & & & & & \\
Current relationship & $18.9(24)$ & $18.1(21)$ & $33.1(294)$ & & $28.60^{* * *}$ \\
Previous relationship & $30.7(39)$ & $44.0(51)$ & $38.4(341)$ & 5.02 & \\
Never & $50.4(64)$ & $37.9(44)$ & $28.5(253)$ & & \\
Males & & & & & \\
Current relationship & $10.0(27)$ & $11.9(10)$ & $19.0(178)$ & & \\
Previous relationship & $42.8(116)$ & $40.5(34)$ & $51.9(487)$ & 0.32 & \\
Never & $47.2(128)$ & $47.6(40)$ & $29.1(273)$ & & \\
\hline
\end{tabular}

Note: $* * * p<.001$. 
Table 2. Bivariate associations between the study variables for the cleft sample: females (above; $n=234$ ) and males (below; $n=342$ ).

\begin{tabular}{lllllll}
\hline & RoA & SoA & CF & PhA & CHASQ & SCL-7 \\
\hline RoA & - & $.53^{* * *}$ & $.30^{* * *}$ & $.47^{* * *}$ & $.40^{* * *}$ & $-.24^{* *}$ \\
SoA & $.45^{* * *}$ & - & $.53^{* * *}$ & $.38^{* * *}$ & $.31^{* * *}$ & $-.42^{* * *}$ \\
CF & $.32^{* * *}$ & $.55^{* * *}$ & - & $.22^{* *}$ & $.24 * *$ & $-.31^{* * *}$ \\
PhA & $.39^{* * *}$ & $.42^{* * *}$ & $.28^{* * *}$ & - & $.69^{* * *}$ & $-.48^{* * *}$ \\
CHASQ & $.23^{* * *}$ & $.28^{* * *}$ & $.14 *$ & $.58^{* * *}$ & - & $-.45^{* * *}$ \\
SCL-7 & $-.19 * *$ & $-.37 * * *$ & $-.29 * * *$ & $-.44^{* * *}$ & $-.33^{* * *}$ & - \\
\hline
\end{tabular}

Note: $* * p<.01 ; * * * p<.001$.

Self-Perceptions profile for Adolescents: $\mathrm{RoA}=$ Romantic Appeal; $\mathrm{SoA}=$ Social acceptance; $\mathrm{CF}=$ Close friendships; $\mathrm{PhA}=$ Physical appearance; $\mathrm{CHASQ}=$ Satisfaction with appearance; $\mathrm{SCL}-7=$ Depressive symptoms. 
Table 3. Hierarchical regression analysis investigating the effect of the study variables on self-perceptions of romantic appeal in the cleft sample $(n=485)$.

\begin{tabular}{lllllll}
\hline & & $B$ & $S E$ & $\beta$ & $s r$ & $R^{2}$ \\
\hline Step 1 & Gender & 0.42 & 0.06 & $.31^{* * *}$ & .30 & .09 \\
& Visibility & -0.11 & 0.06 & -.08 & -.08 & \\
& Additional Condition & -0.09 & 0.07 & -.06 & -.06 & \\
Step 2 & Gender & 0.17 & 0.06 & $.12^{* *}$ & .13 & .26 \\
& Visibility & -0.03 & 0.06 & -.02 & -.02 & \\
& Additional Condition & -0.14 & 0.06 & $-.09^{*}$ & -.10 & \\
& Appearance (CHASQ) & 0.02 & 0.02 & .05 & .04 & \\
& Physical Appearance (PhA) & 0.36 & 0.06 & $.42^{* * *}$ & .32 & \\
Step 3 & Gender & 0.14 & 0.06 & $.10^{*}$ & .11 & .36 \\
& Visibility & -0.07 & 0.06 & -.05 & -.06 & \\
& Additional Condition & -0.11 & 0.06 & -0.07 & -.09 & \\
& Appearance (CHASQ) & 0.00 & 0.02 & .00 & .00 & \\
& Physical Appearance (PhA) & 0.26 & 0.05 & $.30^{* * *}$ & .24 & \\
& Social Acceptance & 0.40 & 0.06 & $.34^{* * *}$ & .32 & \\
& Close Friendships & 0.01 & 0.05 & .01 & .01 & \\
Step 4 & Gender & 0.13 & 0.06 & $.09^{*}$ & .10 & .41 \\
& Visibility & -0.02 & 0.06 & -.02 & -.02 & \\
& Additional Condition & -0.10 & 0.06 & .10 & -.08 & \\
& Physical Appearance (PhA) & 0.28 & 0.05 & $.32^{* * *}$ & .27 & \\
& Social Acceptance & 0.36 & 0.05 & $.30^{* * *}$ & .29 & \\
& Close Friendships & -.01 & 0.05 & -.01 & -.01 & \\
& Previous relationship & -0.31 & 0.05 & $.23^{*}$ & .28 & \\
\hline
\end{tabular}

Note: $* p<.05 ; * * p<.01 ; * * * p<.001$. 
Table 4. Mean scores and standard deviations across the three study samples for depressive symptoms and global self-worth in females and males who reported being in a current romantic relationship, having been in romantic relationship, and those with no experience of romantic relationships.

\begin{tabular}{lllllll}
\hline Depressive symptoms & \multicolumn{6}{c}{ Romantic relationships } \\
\cline { 2 - 7 } Females & $n$ & Total & Current & Previous & Never & $F$ \\
\cline { 2 - 7 } Nonvisible cleft & 112 & $1.66(0.62)$ & $1.64(0.66)$ & $1.79(0.69)$ & $1.52(0.49)$ & 2.06 \\
Visible cleft & 126 & $1.72(0.58)$ & $1.88(0.73)$ & $1.73(0.54)$ & $1.66(0.53)$ & 1.36 \\
$\quad$ Reference group & 880 & $1.86(0.60)$ & $1.87(0.61)$ & $1.89(0.61)$ & $1.86(0.60)$ & 1.67 \\
Males & & & & & & \\
$\quad$ Nonvisible cleft & 82 & $1.44(0.38)$ & $1.63(0.41)$ & $1.35(0.31)$ & $1.45(0.40)$ & 2.79 \\
$\quad$ Visible cleft & 259 & $1.33(0.36)$ & $1.47(0.50)$ & $1.33(0.34)$ & $1.30(0.35)$ & 2.45 \\
Reference group & 928 & $1.64(0.55)$ & $1.69(0.57)$ & $1.63(0.55)$ & $1.63(0.55)$ & 0.89
\end{tabular}

Global Self-Worth

\begin{tabular}{lllllll} 
& \multicolumn{6}{c}{ Romantic relationships } \\
\cline { 2 - 7 } Females & $n$ & Total & Current & Previous & Never & $F$ \\
\cline { 2 - 7 } Nonvisible cleft & 114 & $2.98(0.30)$ & $3.06(0.81)$ & $2.82(0.76)$ & $3.12(0.61)$ & 2.19 \\
Visible cleft & 130 & $2.80(0.70)$ & $2.76(0.82)$ & $2.73(0.77)$ & $2.82(0.63)$ & 0.21 \\
$\quad$ Reference group & 880 & $2.76(0.68)$ & $2.80(0.64)$ & $2.75(0.71)$ & $2.73(0.71)$ & 0.69 \\
Males & & & & & & \\
$\quad$ Nonvisible cleft & 84 & $3.28(0.53)$ & $3.08(0.52)$ & $3.32(0.59)$ & $3.30(0.54)$ & 0.76 \\
Visible cleft & 275 & $3.40(0.48)$ & $2.36(0.46)$ & $3.44(0.44)$ & $3.34(0.53)$ & 1.20 \\
Reference group & 943 & $3.14(0.59)$ & $3.14(0.60)$ & $3.18(0.58)$ & $3.06(0.61)$ & $3.05^{*}$ \\
\hline
\end{tabular}

